\title{
Research on the Strategic Choice of Brand Development of Agricultural Products in Jilin Province Driven by Financial Service Innovation
}

\author{
Lan Zhang ${ }^{1, a}$, Zihong Zhao ${ }^{2, b}$, Jinhui Zhang ${ }^{3, \mathrm{c}}$ and LingDing ${ }^{4, d,{ }^{*}}$ \\ ${ }^{1}$ School of Accounting, Jilin University of Finance and Economics, Changchun, China \\ ${ }^{2}$ School of Accounting, Jilin University of Finance and Economics, Changchun, China \\ ${ }^{3}$ School of Accounting, Jilin University of Finance and Economics, Changchun, China \\ ${ }^{4}$ School of Accounting, Jilin University of Finance and Economics, Changchun, China

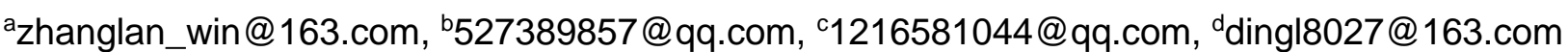

Keywords: Financial services, Innovation driving, Brand of agricultural products, Strategic choice.

\begin{abstract}
The No.1 document of the central government in 2019 clearly points out that it is necessary to get through all aspects of financial services for agriculture, rural areas and farmers, and encourage banking financial institutions to increase the medium and long-term credit support for rural revitalization and poverty alleviation, so as to promote the financial resources to the agricultural and rural development from the policy level. In this paper, we define the goal of financial service innovation to drive the brand development of agricultural products in Jilin Province through SWOT analysis of the brand development of agricultural products in Jilin Province. On this basis, this paper proposes that we should deepen rural financial reform, promote rural financial services and product innovation, strengthen rural credit construction, enhance the ability of capital market to support agriculture, rural areas and farmers and accelerate the establishment of agricultural brand in Jilin Province as the strategic focus of the development of agricultural brand in Jilin Province.
\end{abstract}

\section{Introduction}

Agricultural products enterprises play a leading role in the process of agricultural development in our country. Modern service industry is a service industry supported by modern science and technology and builds on the basis of new management concept, operation mode and organization mode. Among the many power engines of the development of modern service industry, financial service industry is an important pillar and driving force. Under a certain financial system, with the help of industrial policy, monetary policy and finance can adjust the industrial investment direction of funds, so as to optimize the brand structure of agricultural products and improve production efficiency.

\section{The SWOT analysis of brand development of agricultural products in Jilin Province}

\subsection{Advantage}

\subsubsection{Advantages of climate conditions}

Jilin Province is located in the northeast of China, $41^{\circ}-46^{\circ}$ north latitude, which belongs to the temperate continental monsoon climate, with dry spring, hot and rainy summer, cool autumn and cold winter. The conditions of light, heat and water in normal years in Jilin Province can not only meet the needs of agricultural production, but also benefit the accumulation of crop nutrition. And it can improve the quality of agricultural products and reduce the probability of occurrence of pests and diseases, which is very beneficial to agricultural production

\subsubsection{Advantages of agricultural resources}

Jilin Province, located in the northeast of China, has rich agricultural resources, such as land resources, forestry resources, and the resources of animal and plant. In 2018, the total land area of Jilin Province is $187400 \mathrm{~km} 2$, including $30.0 \%$ plain, $28.2 \%$ platform, $5.8 \%$ hills and $36.0 \%$ 
mountains. The land available for agricultural production is relatively rich. In addition, Jilin Province has Changbai Mountain forest area, which is one of the six largest forest areas in the country. The Changbai Mountain Range stretches for thousands of miles, known as the "Changbai forest sea". There are many kinds of forest resources and abundant reserves.

\subsection{Disadvantage}

\subsubsection{Lack of integrated planning for agricultural product brands}

At present, in the process of brand building, some agricultural production enterprises in the province often blindly launch new products without research, which are separated from the market and consumers. There is no comprehensive and systematic brand plan, only some one-sided efforts, and finally it is difficult to become a successful brand, because they have a one-sided understanding of the brand, and only do one aspect and one part of the brand. For example, only advertising, only packaging or only channels. Few agricultural production enterprises put all aspects of the brand in place.

\subsubsection{Poor marketing and insufficient funds affect the development and growth of the brand}

The establishment of a brand and the expansion of its influence are influenced by many factors. Among them, improving smooth marketing channels and wide coverage of publicity and promotion are powerful means to expand brand awareness, but they all need financial support, especially publicity and promotion, which is the key factor restricting the development of agricultural products brand in Jilin Province.

\subsection{Opportunity}

\subsubsection{The change of agricultural products sales mode makes the brand building of agricultural} products necessary

The retail trade of agricultural products in China mainly takes place in the urban market, and the mode of urban retail trade of agricultural products is changing from market sale to supermarket sale. In large and medium-sized cities, the number of agricultural products sold by supermarkets has reached more than $1 / 3$ of the total sales volume, and is developing at a relatively fast speed, which may become the main way for urban residents to purchase agricultural products. The rapid development of supermarket sales mode provides opportunities for brand agricultural products to expand market share, at the same time it excludes non brand agricultural products from entering the market.

\subsubsection{The development of new agriculture provides more opportunities for brand building of agricultural products}

With the development of science and technology and the improvement of living standards of urban and rural residents, there are many new forms of agricultural production, such as green agriculture, sightseeing agriculture, eco-agriculture and so on. At present, there are nearly 3000 agricultural parks of various types in China, and 359 agricultural tourism demonstration sites have been selected, covering 31 provinces and cities in China, which have set up a model for the development of sightseeing agricultural tourism in agriculture, forestry, animal husbandry and fishery industries.

2.3.3. The rapid development of e-commerce of agricultural products provides new ideas for brand building of agricultural products

The application of Internet technology has injected new vitality into the circulation of agricultural products in China. From the traditional mode of agricultural products trading to the integration of various resources, the Internet technology uses advanced and convenient technology to build agricultural information application platform, and implements agricultural products trading on the network, which has a great role in improving China's agricultural value chain and improving agricultural competitiveness.

\subsection{Threat}

\subsubsection{Intensified market competition}

In recent years, the state has adopted a series of macro-control policies around maintaining growth, expanding domestic demand and adjusting structure, which provides a relatively loose domestic 
market environment for the development of China's agricultural products industry. However, with the development of agricultural products industry in various regions of the country, the market competition is becoming more and more intense. The marketing of agricultural products in Jilin Province is facing the market competition and challenges from home and abroad.

\subsubsection{Threats from counterfeit brands}

In recent years, there are more and more cases of making and selling fake products, and there are many fake brand products in the market. Because of the lack of brand management, agricultural products have become a disaster area of making and selling fake products, which seriously threatens the survival and development of agricultural products brands

\section{The goal of financial service innovation driving the brand development of agricultural products in Jilin Province}

By 2020, Jilin Province will gradually establish a rural financial system with complete structure, clear hierarchy, clear division of labor and complementary functions, with continuous expansion of coverage and improvement of service level, so as to meet the financial needs of different subjects through diversified channels. By 2025, we will establish a rural financial service system that guarantees comprehensive, functional, safe, stable and honest standards, and ensure that the growth rate of loans for agriculture, rural areas and farmers will not be lower than the average growth rate of loans in that year, and the loan increase will not be lower than the same period last year. Through financial service innovation to promote the brand development of agricultural products in Jilin Province, by 2020, with the theme of "black land, Guandong sentiment, ecological Jilin grain", we will create a brand image of green agricultural products in Jilin Province with high visibility and influence, with a brand value of more than 10 billion. We will focus on cultivating 50 public brands, 200 enterprise brands and 500 product brands in famous regions such as rice, miscellaneous grains and beans, ginseng, velvet antler and edible fungus. By 2025, we will establish and improve the agricultural brand system with regional public brand as the core, enterprise brand as the support and product brand as the basis, strive to build famous and excellent products such as "Jilin rice" and "Changbaishan ginseng" into national agricultural brands, seize the international high-end market, and realize the transformation from a large agricultural product province to a large brand province.

\section{Strategic focus of financial service innovation driving brand development of agricultural products in Jilin Province}

\subsection{Deepen the rural financial reform}

We will accelerate the reform of supporting agriculture in large and medium-sized financial institutions, strengthen the development of loans for agricultural enterprises by the agriculture, rural areas and farmers business unit of the Agricultural Bank of China, optimize the outlets of institutions below the county level of the postal savings bank to develop microcredit, and strengthen medium and long-term loans such as infrastructure development for agricultural development. We will encourage large and medium-sized financial institutions to decentralize the authority to approve loans and expand the business authorization of county sub branches. Maintain the stability of the county legal person organization of rural credit cooperatives, and ensure that outlets and businesses are close to the grassroots level. We should actively support the development of small and micro financial organizations in rural areas and encourage private capital to participate in the establishment of rural banks.

\subsection{Strengthen the construction of rural credit}

Scientific evaluate the credit users and credit villages and towns, strengthen the integration of credit information, and strengthen the punishment of dishonesty. To explore and innovate the new rural operation organization rating \& loan, relying on external or internal rating agencies, rating the new agricultural operation entities such as large farmers, family farms, farmers' professional cooperatives, and the banking institutions issue credit loans according to the rating results. We 
should standardize the development of rural cooperative finance, adhere to the principles of membership system, closeness and democratic management, and select professional farming cooperatives with democratic management, standardized operation and strong driving force to cultivate and develop rural mutual funds.

\subsection{Enhance the ability of capital market to support agriculture, rural areas and farmers}

We will improve the agricultural insurance system and gradually reduce the proportion of premium subsidies for major grain crop insurance in major grain producing counties. We will expand the coverage of financial insurance premium subsidies and improve the level of risk protection, encourage insurance institutions to explore the development of special agricultural product insurance, and explore the establishment of a mechanism to disperse the risk of agricultural disasters. We will increase the variety of products such as vegetable basket futures, promote the integration of futures and spot markets, and strengthen the training of futures knowledge for cooperatives and leading enterprises. Encourage agricultural enterprises to expand financing channels through multi-level capital market, raise production and development funds through issuing stocks, bonds, short-term financing bonds, medium-term notes and other financing tools, and reduce financing costs.

\subsection{Accelerate the establishment of agricultural brands in the whole province}

Strengthen the top-level design of agricultural brand management in the whole province. Promote the establishment and integration of regional public brands, increase the integration of rice, ginseng, velvet antler, edible fungus, wine, beef cattle, broiler, pig and other brands, carry out public brand selection activities in ten regions of Jilin Province, focus on the introduction of a number of provincial public brands such as Jilin healthy rice, Jilin assured meat, as well as Shuangyang Sika Deer and Yanbian Yellow with distinctive regional characteristics Niu, Changbai Mountain Ginseng and other local public brands. Implement the strategy of animal husbandry brand, enlarge the existing brands such as Haoyue and Huazheng, and accelerate the cultivation and development of geographical indication brand focusing on Shuangyang Sika Deer, Tongyu grassland red cattle, Yanbian Yellow Cattle. Leading agricultural enterprises, farmers' cooperatives, family farms and other new agricultural economics

\section{Reference:}

[1] Yao Zhanqi, Xia Jiechang. Promoting the integration and interaction of modern financial service industry and scientific and technological progress[J]. Shanghai finance, 2007 (03): 9-13.

[2] Yunlei. Analysis and Research on financial innovation mode of Internet supply chain [J]. Economic Research Guide, 2013 (29): 169-170.

[3] Wang Chunhui. Research on innovative development strategy of rural financial service mode[J]. Agricultural economy, 2019 (11): 106-107. 